\title{
The challenges of mathematics education for Indigenous teacher training
}

\section{Maria Elena Gavarrete}

To cite this article: Maria Elena Gavarrete (2015) The challenges of mathematics education for Indigenous teacher training, Intercultural Education, 26:4, 326-337, DOI: 10.1080/14675986.2015.1073878

To link to this article: http://dx.doi.org/10.1080/14675986.2015.1073878

\section{曲 Published online: 15 Dec 2015.}

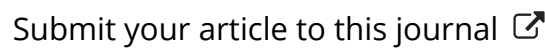

\section{Џ Article views: 36}

Q View related articles $₫$ 


\title{
The challenges of mathematics education for Indigenous teacher training
}

\author{
Maria Elena Gavarrete* \\ Universidad Nacional de Costa Rica, Facultad de Ciencias Exactas y Naturales, Escuela de \\ Matemática, Heredia, Costa Rica
}

\begin{abstract}
In this article, I outline research carried out on in an Ethnomathematics course designed to train Indigenous teachers in Costa Rica, in which the following ethnic groups participated: Ngabes, Bribris, and Cabecares. The challenge is to develop a mathematical education that provides equitable conditions for the different groups within innovative curricular proposals. This research is based on the construct of 'Cultural Mathematical Knowledge' which serves to describe intrinsic characteristics of socially differentiated groups and thus propose a model for teacher education. The design of the course incorporates an empirical base, a theoretical base, and a methodological base. It is a multicultural and multidisciplinary proposal based on Indigenous mathematics and on the ideas of mathematical enculturation, to be developed through curricular microprojects in Indigenous schools. The course promotes preparing the teacher as a researcher to shape him or herself mathematically, as someone who carries out appropriate educational actions in an academic environment in accordance with an ethnolinguistic reality, a cultural worldview, and awareness of the potential of the students of Indigenous schools.
\end{abstract}

Keywords: Indigenous Ethnomathematics; Cultural Mathematical Knowledge; mathematical enculturation; curricular microprojects; teacher training

\section{Contextualization of the research}

This article addressing teacher training based on Indigenous Ethnomathematics is based on part of my doctoral thesis (Gavarrete 2012). The aim of the research was to contribute, from the perspective of Ethnomathematics and teacher training, to the appreciation of interculturality as a transcendental element of pedagogical action, and to seek answers to the following questions:

- How does one include a cultural component of mathematics in a professional educational program?

- How does one identify the specific knowledge necessary to uncover the cultural component of mathematics in Indigenous environments?

- What do the teachers need to emphasize in their education to develop mathematical education from an Indigenous perspective?

- How does one achieve an intercultural contextualized design for mathematical education?

*Email: maria.gavarrette.villaverde@una.cr 
In the search for answers, the need to promote reflective processes in the teachers in training about the application of mathematics in daily situations was considered. Also considered was the need to encourage activities that permitted them to identify the presence of mathematical knowledge within ancestral knowledge in order to promote meaningful learning for the students.

The main question guiding the research was: How does one utilize Ethnomathematics as a fundamental theory in teacher training to combat the exclusion of Indigenous cultural diversity in the mathematical education of Costa Rica? In order to respond to this question, two general proposals were formulated. The first was to identify and characterize the cultural mathematic knowledge of some ethnic groups of Costa Rica, and the second was to develop a training model for teachers who work in Indigenous environments in which knowledge of their own Ethnomathematics is integrated.

The first general proposal was centered around the development of theoretical and empirical grounds to support the proposed model for teacher training. The four specific components of this proposal were as follows: identifying elements of the Cultural Mathematical Knowledge (CMK) of the Ngabes, Bribris, and Cabecares ethnic groups of Costa Rica; characterizing the features of CMK of those ethnic groups; examining the appropriateness of designing an educational program for teachers incorporating the cultural vision of mathematics; and selecting elements of Indigenous mathematics of Costa Rica to incorporate in the design for teacher training.

The development of the second general proposal centered on the didactic proposal to educate teachers that work in Indigenous environments through adopting Ethnomathematics as a primary theoretical basis. Four specific components of this proposal were identified as follows: designing an educational proposal for the teaching of mathematics to promote multicultural competency in Indigenous teachers; implementing that proposal with teachers in the initial training connected with any of the Indigenous groups on which the research is centered, carrying out an evaluation of the educational proposal through analysis of the information collected during the implementation; and proposing a stable educational program for professors in which Ethnomathematics is considered a primary fundamental basis.

Next, I describe the challenges and outline the historical context that constitute part of the motivation behind the research.

\section{The relationship between sociocultural diversity and mathematical education in Costa Rica: Premises and conjectures of the research}

There are various premises that are reflexively related to the research hypotheses, but a few have been selected due to their relevance to the themes of this article. (The reader is encouraged to consult my doctoral thesis (Gavarrete 2012) for a deeper understanding of the approach that supports the focal points of the work).

An ethnocentric vision of mathematics has prevailed in the environment of mathematical education in Costa Rica. It has distorted or limited the educational process for mathematics, especially in Indigenous environments. The programs of study, the textbooks, and other curricular elements have given little attention to the country's minority cultures in rural areas.

Some Costa Rican researchers have come to the opinion that Costa Rican mathematics education has entered a substantial transitional period for theory and practice 
in which the range of mathematical knowledge and its pace of growth require a serious reconsideration of curriculum, texts, material and human resources and, of course, the role of educators.

A premise of my research is the necessity of questioning the exclusion (and the inequity) of current practices in teaching mathematics in different regions of Coast Rica, and in particular in Indigenous contexts. Hence, the design of my research takes into account diverse theoretical and methodological proposals related to Ethnomathematics that can influence the ongoing learning processes of mathematics teachers, enrich pedagogy, and combat the historical exclusion promoted by a monocultural curriculum. The subject of mathematical knowledge that is connected to cultural knowledge is addressed as having an effect on the sense of cultural identity and as a means to enrich learning about vernacular knowledge, from the perspective of Ethnomathematics. From a sociological point of view, it is assumed that Costa Rica has tensions within national identity in which economic conflict, social disadvantages, and cultural differences feed into discrimination and misinformation in the understanding of Indigenous cultures.

Gaete and Jiménez (2011) considered pedagogical aspects and social factors linked to teacher training from the point of view of interculturality, and revealed a lack of competence in the initial training and the absence of possibilities for continuing education of the teachers in sociocultural aspects, whereby receiving quality education with respect to the framework of cultural diversity is limited to a few communities. This situation leads to a lack of awareness of the country's multiculturalism.

The monocultural and Eurocentric perspective has long had a global historical nature. For many years, attention was given only to an occidental view of Mathematics. This ethnocentric view has been predominant in history, resulting in the curricular decontextualization of educational programs, academic resources, and in the professional training of teachers.

Given the aforementioned, it was proposed as another investigative conjecture that there is a need to offer teacher training in intercultural mathematical education to combat marginalization and segregation, to promote respect, and to elevate the dignity of Indigenous Costa Ricans whose ethnic autonomy and cultural idiosyncrasy has been historically suppressed. The 'informal' mathematical knowledge of these Indigenous groups, besides having little or no recognition, has not been common knowledge in Costa Rica (Gavarrete and Oliveras 2010).

The research strongly indicates a separation between cultural knowledge and academic mathematical knowledge, and this 'clash' is discussed regarding the two kinds of knowledge. The dominance of formal mathematical knowledge influences academic success or failure in rural communities and in Indigenous environments, as the education that is offered is standardized for the whole country within a Eurocentric framework. It is a 'universal' curriculum that does not respect regional diversity on a local or sociocultural level.

Teacher training founded on Ethnomathematics has the potential to generate changes in the field of mathematical education in Costa Rica through research and practice. For this reason, a methodology of integrated learning/teaching was promoted, encompassing both the occidental view of mathematics as well as the indigenous view of mathematics. On this basis, a proposal could then be developed that would enrich planning competency for mathematics education. The central idea is to encourage a sociocultural vision of mathematics in order to break away from 
structures of exclusion caused by mono-cultural curricula and also to address the challenge of transcending ethnocentrism and enriching the process of teaching and learning mathematics through the incorporation of Ethnomathematics in professional training and academic environments.

\section{The principal fundamental basis: CMK, Ethnomathematics, and educational aspects}

The conceptual framework and the fundamental basis of the research was separated into three major components: Cultural Indigenous Knowledge, Ethnomathematics, and multicultural education of teachers.

The review of Cultural Indigenous Knowledge brought together diverse authors with regard to structural anthropology, such as Lévi-Strauss (2008) and symbolic anthropology, such as White (1947), and the work of other ethnologists, sociologists, and linguists.

Ethnomathematics and the multicultural education of teachers had as theoretical foundations the ideas of D'Ambrosio $(1985,2006,2007)$ regarding Ethnomathematics and the work of Bishop (1988a, 1988b, 2001) with regard to teacher training and curricular development based on the concept of mathematical enculturation. Also, the ideas of Oliveras (2005) regarding curricular microprojects are based on Ethnomathematics. The theoretical foundations were also strengthened with the support of other relevant authors, such as Gerdes $(1996,1998)$ and do Carmo Santos Domite (2010).

In this work, Ethnomathematics is conceived of as an aspect of mathematical education that studies the development of knowledge of a cultural group ruled by mythic traditions and cosmology that underlie their behavior through how they perceive and interpret the world, and the tangible and intangible relationships of the elements (Gavarrete 2012).

Among the relevant material in the review of the cited work is a deeper understanding of the ideas of D'Ambrosio (2006) who stated that 'Ethnomathematics should not be understood as the study of diverse ethnic mathematics, rather as the study of distinct forms of knowledge' in order to generate such questions as:

- What are the distinct forms of knowledge?

- How does one recognize these distinct forms of knowledge?

- How does one involve them in the educational and learning process of mathematics?

- How to encourage in teachers the intellectual curiosity to recognize and identify these other forms of knowledge?

In an attempt to find an answer to these questions, previous work carried out by the author (Bengoechea, Oliveras, and Gavarrete 2010; Gavarrete and Oliveras 2010) was taken into account, in which 'forms of knowledge' were identified and described in terms of the dynamic processes of representing, understanding, and classifying the world. These forms are present in the social dynamics and the Indigenous worldviews of Costa Rican ethnic groups. A construct was proposed in the research (Gavarrete 2012) that constitutes a contribution to the international Ethnomathematics program, facilitating the characterization of specific Ethnomathematics, namely CMK. 
For the development of this construct, Indigenous knowledge was recognized as an individual, traditional, and local knowledge "that exists within specific conditions of men and women in a particular geographical area and that is developed around them'. (Grenier 1999, 1), wherein systems of knowledge taken from the collective are dynamic (new knowledge is always being added), but they are strictly ruled by the myths and rites that define their cultural heritage and idiosyncrasies. Such systems can produce innovation from within, and can also internalize, use, and adapt external knowledge, thus ensuring survival and cultural significance.

CMK has in turn some indicators that facilitate identification and description of the elements of ancestral cultural heritage that can be an object of study in Ethnomathematics. It alludes to 'living Indigenous mathematics' (Gavarrete 2012) which is understood as mathematics that possess a holistic sense of reality that allows the establishment of a conceptual structure through which the world and its relationships between tangible and intangible objects are understood, connected, and represented. 'Living mathematics' exists in a historical, geographic, and social context.

The indicators or attributes of CMK may be divided into four aspects:

- It is flexible and dynamic because it manifests differently in cultures and periods.

- It is holistic and transdisciplinary because it deals with a model that is composed of knowledge in distinct areas, and that is devised and applied from the inside with an integrative nature.

- It is a tool for survival and transcendence within a cultural group because it organizes learning to be able to deal with the present, and to resort to memory to be able to deal with problems in the future.

- It adds to the definition of human behavior because in the process of acquiring knowledge, it is understood as a result of an individual and cultural process in that behavior is defined and enriched by the elements of the environment.

\section{Cultural Mathematical Knowledge}

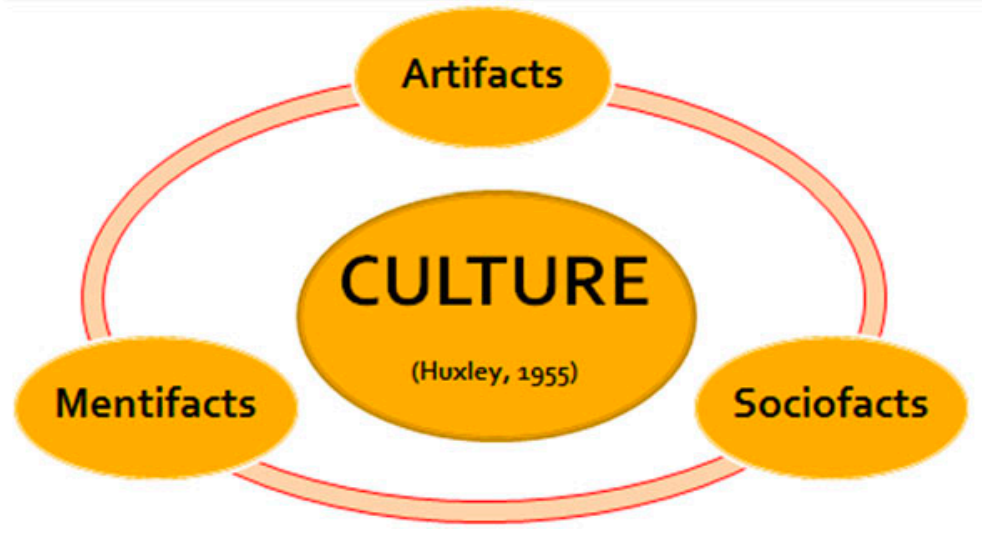

Figure 1. Characterization of CMK. 
In Indigenous environments, in particular, the identification and characterization of CMK is facilitated by a cultural model (Huxley 1955) in which artefacts, mentifacts, and sociofacts (described below) are integrated, as shown in Figure 1.

Based on the ideas of the cited authors, as well as my previous research, the challenge of mathematical education in Indigenous teacher training was confronted, and a model for an Ethnomathematics course was proposed for teachers working in Indigenous environments. The model was implemented and evaluated with teachers from the Cabecar ethnic group through a sequential methodology that will that be described next.

\section{Implemented methodology and principal results}

The research was carried out within the qualitative-interpretative paradigm, addressed through ethnographic research, whereby a sociocultural perspective and the special characteristics of Indigenous participants were considered. In addition, the methodology constructed for the development of the thesis was based on a sequential structural design, constituting an ethnographic spiral (Sandín 2003), in which temporal, chronological, and sequential logic are employed for scientific validity through a process of investigative crystallization, incorporating triangulation also as a tool in the process.

In the first loop of the design spiral, Study 1 consisted of an ethnological study of Indigenous mathematics among the Ngabe, Bribri, and Cabecar peoples. It was carried out within the research to compare ethnography through a sociocultural mapping of identified Indigenous mathematics. In the second loop, the succeeding Study 2, Study 3, and Study 4 yielded conclusions developed by gathering elements related to contextualization, providing an empirical foundation for the design of the educational model.

In the final loop of the design spiral, a classroom ethnography was carried out with Cabecar Indigenous teachers in which the educational model was implemented and evaluated.

\section{Some relevant results from Study 1}

The first study established and verified the characterization of CMK. It was carried out in situ by Indigenous teachers through an inventory of cultural symbols (Oliveras 2005). In this inventory, Indigenous teachers characterized CMK through examples of the application of mathematical thought in daily situations, their own cultural characteristics that related to mathematical thought, external cultural characteristics that related to mathematical thought, and the presence of geometrical thinking in the cultural environment in which the teaching was executed.

To facilitate this process, the cultural model shown in Figure 1 provided a framework:

- Mentifacts are central elements and are more culturally durable. They include language, myths, artistic traditions, and folklore. They are basically abstract and mental elements. They relate to the human capabilities of thought and the formulation of ideas, and they conform to the ideals and images by which other cultural aspects are measured. 
- Sociofacts are those cultural aspects that are related to the connections between individuals and groups. On the individual level, they include family structure, reproductive and sexual behavior, and the raising of children. On a group level, they include political and educational systems.

- Artefacts are the material manifestations of culture. They are also called 'cultural merchandise' and these material technological aspects of a group can satisfy basic needs such as food, shelter, transportation, and the like. Systems such as land use and agricultural production are cultural artefacts, as are tools and particular styles of dress. CMK is also linked to artistic knowledge, agricultural knowledge, and mythical knowledge.

The following are a few specific results.

CMK is connected to the study of the conical house by way of a particular spatial concept in which a distinct logical structure is applied within a worldview. Here, it is possible to validate that CMK is connected to mythic knowledge given that the speculative view of the cosmos has eight organized levels: four above (supra-world) and four below (underworld), in which four planes of mythic reality rule the behavior and actions of the inhabitants of these communities. This is shown in Figure 2.

A prominent feature of CMK among these peoples is the number four as a ritual magic number. The salience of this number constitutes evidence of the organization of thought in Indigenous communities as a strategy to summarize and record ancestral information because it is present in the interpretation of iconographic structures of the Indigenous worldview and in mythic history. It is also closely associated with ritual tradition, such as cleansing or purifying rituals.

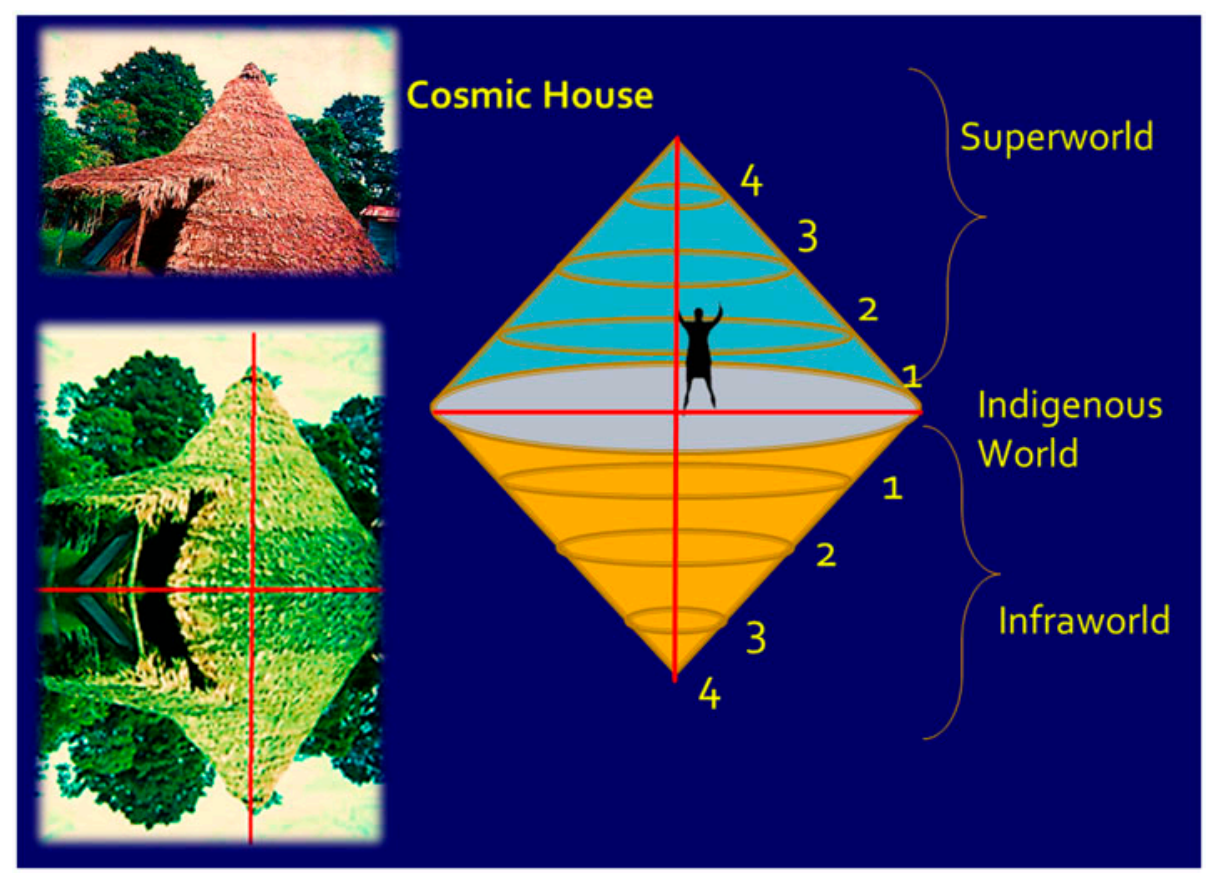

Figure 2. Speculative view of the universe/cosmos based on the cosmic conical house. 
CMK is associated with classification systems that actively survive through oral tradition. A metaphorical and symbolic logic is applied to the studied ethnic groups in which cosmogony uses other representational systems. In other words, the physical world is symbolic of the mythical world, which is a qualifying system.

Classification systems are studied linguistically within an Ethnomathematical perspective. The three observed groups do not have written languages, and belong to the linguistic family of the Chibchan. The three studied languages use numeric classification to identify objects that are arranged or counted according to their geometric shape: long, flat, round, among others. In the particular case of the Cabecar language, a numeric metaphor 'sa'jula' is used, which alludes to the fingers to refer to the number five. As a result, a base five system is used for oral quantification, with a combination of numeric classifiers. Multiples of five generally use the language relating to the flat class for their articulation because the palm of the hand is flat, but when objects are counted that are not multiples of five or that have a form other than flat, a combination of numeric classifications is used. The aforementioned translates to quite a challenge for formal mathematicians because children learn in the native language that carries within it an implicit classification system. This particularity is therefore an element that should be taken into account in teacher training programs in mathematics; however, it is normally not done.

This specificity regarding classification systems in the Indigenous communities of Costa Rica begs for a reflection on the lack of contextualized academic resources and on the significant pedagogical challenge that accompanies the teaching of arithmetic in a culture that uses diverse systems of numeric classifications that differ from formal academic mathematics as adapted for schooling. For this reason, critical content was established for the design of the 'Ethnomathematic Course Model to Educate Teachers in Indigenous Environments' (ECMETIE) model, in which the act of 'classifying' as an essential design element was incorporated. It was complemented by six universal mathematical activities: counting, measuring, locating, designing, playing, and explaining, as posited by Bishop (1988a).

\section{Conclusions reached from Studies 2, 3, and 4}

The design of the ECMETIE model is empirically based on the contributions of Study 1 and on the findings from Studies 2, 3, and 4, whose methodologies and principal results are described below.

Study 2: This consisted of an inquiry among academic and cultural professionals with respect to Ethnomathematics and teacher training. Thirty professionals participated. They completed a questionnaire that was collectively and individually analyzed. A principal finding that stood out was that the professionals linked mathematics and culture, and revealed a lack of Ethnomathematical education. They also suggested that an investigative spirit be encouraged in workshops or seminars, and that they be carried out in the initial training.

Study 3: This consisted of an inquiry among Indigenous teachers about mathematics, education, and culture in which 69 teachers participated. The responses of those who were given the questionnaire were augmented by ethnographic interviews, followed by analysis using deductive categories. The most important finding was that the teachers recognized the relationships between CMK and academic mathematical content. They made an inventory of cultural objects with mathematical content, and stated the importance of applying CMK in schools. 
Study 4: This consisted of a study of realities and expectations for the Indigenous teachers' course. This was centered on determining relevant aspects with regard to the planning of teacher training by way of a panel of 11 professionals, the output from which was analyzed through generating qualitative categories. The main findings recognized the difficulties in realizing CMK and the need for a course contextualized by Ethnomathematics, which resulted in the intervention by the author in designing the course to educate Cabecar teachers.

\section{Important elements of the design, implementation, and evaluation of the ECMETIE model}

The design of the ECMETIE model was carried out in Spain between 2010 and 2011 and was implemented in Costa Rica during the second semester of 2011, as well as through involvement in a course entitled 'Mathematical Education in Multicultural Contexts', which corresponded to the study plan for the major of 'Bachelors in Education with an emphasis on Cabecar language and culture'. This course was based on a multicultural and transdisciplinary educational proposal that combined elements from the Ethnomathematics program (D'Ambrosio 2006), as well as theoretical elements concerning mathematical enculturation (Bishop 1988a), and as materialized through microprojects for intercultural education (Oliveras 2005).

An important finding that stood out was that the Indigenous teachers that participated in the course reflected on their teaching practices and experienced a multicultural pedagogy in which awareness of cultural 'otherness' was developed. It also emphasized and encouraged educational empowerment regarding understanding of CMK.

The evaluation of the ECMETIE model was carried out through analysis of its implementation, and suggested that the ECMETIE model is viable for other ethnic/cultural groups, and is pertinent because it allows recognition of Indigenous CMK. Thus, it strengthens cultural identity and contributes to teacher training from an intercultural perspective on mathematics.

\section{Conclusions and reflections on the results of the research}

The development of the ECMETIE model poses a challenge to educational creativity in terms of developing and integrating an intercultural mathematics curriculum.

The research, in and of itself, poses a new challenge by coming to deeper conclusions about Indigenous CMK - in particular, about the enigmas that arise in the study of Indigenous languages from an Ethnomathematical point of view, and about the meanings associated with mythic knowledge in the Indigenous cosmogenic structure that represents a different understanding of reality.

With regard to the Indigenous Ethnomathematicians of Costa Rica, it was concluded that the common findings in the three ethnicities can be used in teacher training and in the academic environment. It was possible to develop a methodology about how to identify Indigenous Ethnomathematics and how to characterize them through various methodologies, such as questionnaires, ethnographic interviews, and especially through an inventory of cultural symbols and their depictions.

With regard to the implementation of the model, it was concluded that the development of the teacher portfolios and the microprojects was evidence of the investigative process and enculturation through the CMK of an ethnic group, in 
which educational planning was encouraged through curricular contextualization tools that favored a transdisciplinary view of knowledge, and generated reflections on the sociocultural value of Ethnomathematics in academic environments.

With regard to the impact of the model on teacher training, it was concluded that the model was implemented and evaluated with satisfactory results. Therefore, it is appropriate and replicable in other groups. It favors the empowerment of teachers about their own CMK and promotes explorations with a multicultural pedagogy.

The investigation contributes to the international Ethnomathematics program as the ECMETIE model shows a way of linking Ethnomathematics in teacher training in specific environments. It also provides a new methodological design of spiral ethnography for future work along the same lines.

The incorporation of Ethnomathematics within the educational efforts of Costa Rica was evaluated on three levels:

- Incorporating into the curriculum elements of sociocultural environments, thereby enhancing motivational factors in learning (Gerdes 1996), facilitating the incorporation of a sociocultural component in the broader curriculum map, and acknowledging the importance of the affective, emotional dimensions in mathematics teaching/learning (Gómez-Chacón 2010).

- Incorporating the mathematical ideas of other cultures that occur in daily life strengthens one's own cultural identity in relation to other cultures, and allows for reflection on the role of mathematics in determining cultural otherness. At the same time, it strengthens Indigenous cultural autonomy, by addressing the challenges posed by UNESCO (2012) with respect to attention to diversity. The UNESCO declaration also stresses avoidance of exclusion and isolation, and the need to help students understand others' cultural contributions, and thus realize the universality of mathematics as a universal human activity.

- Incorporating the sociocultural component in teacher training programs, envisioning mathematics as a typical human activity in all cultures - as well as a social phenomenon - thus contributing to a functional vision of the notion of mathematical practices (D'Ambrosio 2006), and allowing the value of mathematical practices to be strengthened (Bishop 1988a).

The inclusion of Ethnomathematical knowledge in training Indigenous teachers contributes to professional development, and, in turn, to the idea of an emerging identity as Ethnomathematicians, that contains both a transdisciplinary vision of knowledge and a reflection on the sociocultural role of mathematics in the construction of knowledge within the Indigenous environments.

Also, the reflections on mathematics, culture, education and society - and the relationships that are maintained between them - can be oriented toward inclusive pedagogical practices in which learning mathematics can address deeper notions of equity (Gavarrete 2013, 2014). Therefore, the idea of incorporating Ethnomathematics as curricular content in educational programs should be reinforced because it poses new challenges for research and pedagogical action. This program constitutes a prospective vision of new research in the field, and at the same time contributes to determining the role of Ethnomathematics in mathematics education. 


\section{Acknowledgment}

Translated from Spanish by Jake Fernandez and Jennie. I would like to thank the members of the indigenous communities, anthropologists, linguists and math education advisors for their support and contribution to the development of this research endeavor.

\section{Disclosure statement}

No potential conflict of interest was reported by the author.

\section{Notes on contributor}

María Elena Gavarrete has a doctorate in Mathematics Education and a masters in Mathematics Education from the University of Granada (Spain). Her bachelor's degree in Educational Science and Mathematics Education is from the National University (Costa Rica). She is the coordinator of the Costa Rica Chapter of the Latin American network of Ethnomathematics, and the Associate Editor of Latin American Review of Ethnomathematics. She currently works as a professor in the Mathematical School of the National University (Costa Rica), and is the director of the Virtual Museum of Mathematical History and Philosophy Project from a Sociocultural View, and collaborates as a consultant in certain governmental contexts to improve teacher training in Ethnomathematics.

\section{References}

Bengoechea, N., M. L. Oliveras, and M. E. Gavarrete. 2010. "Estructura de la numeración en la cultura Bribri [Structure of Numeration in the Bribri Culture]." In Memorias del Segundo Congreso Internacional de Enseñanza de la Matemática [Proceedings of the 2nd International Congress of Mathematics Education], edited by Y. Morales, 127-134. Heredia: Universidad Nacional de Costa Rica.

Bishop, A. J. 1988a. Mathematical Enculturation. Dordrecht: Reidel.

Bishop, A. J. 1988b. "Mathematics Education in Its Cultural Context." Educational Studies in Mathematics 19: 179-191.

Bishop, A. J. 2001. "Lo que una perspectiva cultural nos cuenta sobre la historia de las matemáticas [What a Cultural Perspective Tells Us About the History of Mathematics]." UNO 26 (8): 61-72.

D'Ambrosio, U. 1985. "Ethnomathematics and its Place in the History and Pedagogy of Mathematics." For the Learning of Mathematics 5 (1): 44-48.

D'Ambrosio, U. 2006. Ethnomathematics: Link between Tradition and Modernity. Rotterdam: Sense Publishers.

D’Ambrosio, U. 2007. "La matemática como ciencia de la sociedad [Mathematics as a Social Science]." In Educación matemática y exclusión [Mathematics Education and Exclusion], edited by J. Giménez, J. Diez-Palomar, and M. Civil, 83-102. Barcelona: Graó.

do Carmo Santos Domite, M. 2010. "The Encounter of Non-indigenous Teacher Educator and Indigenous Teacher: The Invisibility of the Challenges." ZDM 42: 305-313.

Gaete, M., and W. Jiménez. 2011. "Carencias en la formación inicial y continua de los docentes y bajo rendimiento escolar en matemática en Costa Rica [Shortcomings in the Initial and Continuing Training of Teachers and Low School Performance in Mathematics in Costa Rica]." Cuadernos de Antropología 6 (9): 93-117.

Gavarrete, M. E. 2012. "Modelo de aplicación de Etnomatemáticas en la formación de profesores para contextos Indígenas de Costa Rica [Model for the Application of Ethnomathematics in Teacher Training for Indigenous Contexts in Costa Rica]." Doctoral Thesis, University of Granada, Spain.

Gavarrete, M. E. 2013. "La Etnomatemática como campo de investigación y acción didáctica: su evolución y recursos para la formación de profesores desde la equidad [Ethnomathematics as a Field of Investigation and Pedagogical Action: Its Evolution and Resources for Teacher Training from the Perspective of Equity]." Revista Latinoamericana de Etnomatemática 6 (1): 127-149. 
Gavarrete, M. E. 2014. “¿Cómo promover educación matemática intercultural y combatir el etnocentrismo? [How to Promote Intercultural Mathematics Education and Combat Ethnocentrism]." In Educación e interculturalidad: dialogando en plural [Education and Multiculturality: Talking Together], edited by M. González, 191-216. San José: Ministry of Public Education of Costa Rica.

Gavarrete, M. E., and M. L. Oliveras. 2010. "Matemáticas, culturas y formación de profesores en Costa Rica [Mathematics, Culture, and Teacher Training in Costa Rica]." Journal of Mathematics and Culture 6 (1): 209-222.

Gerdes, P. 1996. "Ethnomathematics and Mathematics Education." In International Handbook of Mathematics Education, edited by A. J. Bishop, M. A. K. Clements, C. Keitel, J. Kilpatrick, and C. Laborde, 909-943. Dordrecht: Springer.

Gerdes, P. 1998. "On Culture and Mathematics Teacher Education." Journal of Mathematics Teacher Education 1 (1): 33-53.

Gómez-Chacón, I. M. 2010. "Tendencias actuales en investigación en matemáticas y afecto [Contemporary Tendencies in Research in Mathematics and Affect]." In Investigación en educación matemática XIV [Investigations in Mathematics Education XIV], edited by M. M. Moreno, A. Estrada, J, Carrillo, and T. A Sierra, 121-140. Lleida: SEIEM.

Grenier, L. 1999. Conocimiento indígena. Guía para el investigador [Indigenous Knowledge: Researcher's Guide]. San José: Editorial Tecnológica de Costa Rica y Centro Internacional de Investigaciones para el Desarrollo-Canadá

Huxley, J. S. 1955. "Evolution, Cultural and Biological." In Yearbook of Anthropology, edited by W. L. Thomas, 2-25. Chicago, IL: University of Chicago.

Lévi-Strauss, C. 2008. Structural Anthropology. New York: Basic Books.

Oliveras, M. L. 2005. "Microproyectos para la educación intercultural en Europa [Microprojects for Intercultural Education in Europe]." Revista UNO 38: 70-81.

Sandín, M. P. (2003). Investigación cualitativa en educación: fundamentos y tradiciones [Qualitative Research in Education: Fundamentals and Traditions]. Madrid: McGraw-Hill, Interamericana.

UNESCO. 2012. Challenges in Basic Mathematics Education. París: Author.

White, L. 1947. "El lugar de la realidad matemática: una referencia antropológica [The locus of mathematic reality. An anthropological reference]." In El mundo de las matemáticas, SIGMA, edited by J. Newman, 282-298. Barcelona: Grijalbo. 